\title{
El oleoturismo: una alternativa para preservar los paisajes del olivar y promover el desarrollo rural y regional de Andalucía (España) ${ }^{1}$
}

\author{
María Genoveva Millán Vásquez de la Torre², Luis Amador Hidalgo ${ }^{3}$ \\ y Juan Manuel Arjona Fuentes ${ }^{4}$
}

\begin{abstract}
RESUMEN
Un aprovechamiento inteligente del capital territorial es fundamental para propiciar el desarrollo regional. En el caso de Andalucía, los paisajes del olivar resultan ser un elemento clave para entender la configuración de su territorio. Desde hace años, la cultura del olivo ha aportado a esta región un gran valor paisajístico y medioambiental. La diversidad de estos paisajes ofrece un marco idóneo para iniciativas que aprovechen, con fines turísticos, todos los elementos culturales vinculados a este cultivo. El oleoturismo permite reforzar el carácter multifuncional de los paisajes del olivar de manera que, aprovechando de forma sostenible los recursos existentes, se contribuya al aumento del bienestar de toda la población rural. En este artículo se presenta al oleoturismo como una alternativa de diversificación económica, para muchas localidades ubicadas en zonas olivareras, y que contribuye a preservar los paisajes del olivar y a promover el desarrollo rural y regional de Andalucía.
\end{abstract}

Palabras clave: Oleoturismo, paisajes del olivar, desarrollo rural y regional.

\begin{abstract}
An intelligent use of territorial capital is fundamental in the promotion of regional development. In the case of Andalusia, olive groves comprise a key element to understand the configuration of the territory. For many years the cultivation of the olive has afforded this region with great landscape and environmental value. The diversity of its landscapes presents an ideal framework for tourism initiatives that make use of all the cultural elements linked to this crop. Olive Oil Tourism allows the multifunctional facets of these olive plantations to be reinforced, so that utilization of this existing resources in a sustainable way contributes to an increase in the well-being of the whole rural population. This article presents olive oil tourism as an alternative for economic diversification in many olive-producing areas that contributes to the conservation of olive-growing areas and to the promotion of ru$\mathrm{ral}$ and regional development in Andalusia.
\end{abstract}

Key words: Olive Oil Tourism, olive grove landscapes, rural and regional development.

1 Artículo recibido el 16 de junio de 2014, aceptado el 10 de diciembre de 2014 y corregido el 16 de enero de 2015.

2 Departamento de Matemáticas e Ingeniería, Universidad Loyola Andalucía (España).

E-mail: gmillan@uloyola.es
3 Departamento de Economía, Universidad Loyola Andalucía (España). E-mail: lamador@uloyola.es

4 Departamento de Matemáticas e Ingeniería, Universidad Loyola Andalucía (España)

E-mail: jmarjona@uloyola.es 
La vinculación entre los conceptos de patrimonio, paisaje cultural y la conformación histórica del territorio resulta de especial actualidad y está siendo objeto de atención a escala internacional. La importancia de la dimensión paisajística del territorio ha sido reconocida en algunas declaraciones internacionales (la Convención del Patrimonio Mundial de la UNESCO celebrada en 1992; la Carta del Paisaje Mediterráneo publicada en 1992, la Convención Europea del Paisaje celebrada en 2000 y la Agenda Territorial de la Unión Europea 2020) que abundan en la necesidad de preservar los paisajes como elemento esencial de la cultura mundial. El territorio constituye, en sí mismo, un recurso cultural y económico de primer orden, lo que remite a un nuevo concepto, el de patrimonio territorial (Ortega Valcárcel, 1998: 33), que hace referencia tanto a su disposición físico-natural como a los recursos patrimoniales disponibles en cada ámbito, incluidos aquellos de carácter intangible que refuerzan la identidad y confieren una mayor competitividad a los territorios. La dimensión territorial posee recursos específicos que son los que marcan las diferencias y acrecientan la competitividad en el contexto socioeconómico actual. En este sentido, cualquier elemento de un territorio puede operar como potencial factor de desarrollo: productos locales, modos tradicionales de obtenerlos, paisajes, alojamientos, arquitectura, hechos históricos relevantes, flora, fauna, ríos y espacios acuáticos, orografía, tradiciones gastronómicas, música, fiestas, ritos, imágenes, modismos, conocimientos, actividades agrarias, etc.

Cada vez se valoran más determinados elementos inmateriales y algunas actividades, relacionados con la identidad territorial, que se revelan como fundamentales de cara a presentar una nueva concepción del desarrollo en zonas rurales, y cuyo valor se corresponde con su pertenencia a la cultura y patrimonio locales. Este es el caso de todo lo que rodea al mundo del olivo, del aceite de oliva y de los paisajes del olivar en Andalucía (España).

En este trabajo se analiza el caso concreto de la región andaluza y cómo una modalidad turística, el oleoturismo, puede contribuir a promover la conservación de los paisajes del olivar en ella ubicados, así como hacer factible un aumento de las rentas percibidas por los habitantes de las zonas rurales productoras de aceite de oliva. En definitiva, se considera a esta actividad turística como una vertiente más del carácter multifuncional de estos paisajes, que puede contribuir a su preservación, a la vez que a diversificar tanto el aprovechamiento de los recursos ligados a la cultura del olivo, como los ingresos provenientes de su explotación, todo lo cual contribuirá a potenciar el desarrollo económico y social de la región. Mediante este tipo de iniciativas turísticas se consigue diversificar las actividades económicas en el medio rural andaluz, vinculando la puesta en valor del patrimonio territorial (los paisajes del olivar) con la promoción del desarrollo rural y regional.

\section{La multifuncionalidad de los sistemas agrarios}

Desde hace tiempo, la figura de los paisajes culturales, ligados a la intervención humana, está siendo objeto de una creciente atención por parte de investigadores y planificadores (Hildenbrand Scheid, 1993; Bennett, 1996; Schmitz et al., 2003). El paisaje es un componente fundamental del patrimonio natural y cultural de muchos países, regiones y comarcas, un elemento clave del bienestar individual y social y un recurso favorable para la actividad económica, capaz de generar empleo, renta y, por tanto, básico para fijar la población en el medio rural y propiciar el desarrollo de esas zonas. En particular, la relación entre agricultura y paisaje es estrecha y tiene ya un cierto recorrido. No obstante, los vínculos tradicionales entre ambos se han renovado y reorientado en las últimas décadas con motivo de, entre otras razones, la asunción académica y normativa de los planteamientos del Convenio Europeo del Paisaje (Consejo de Europa, 2000).

En general, determinados paisajes agrarios reciben una especial atención desde una perspectiva patrimonial. En este sentido, encontramos ejemplos como el de los regadíos tradicionales (Mata y Fernández, 2010; Hermosilla Pla, 2010; Silva Pérez y Orozco Frutos, 2011), la dehesa (Silva, 2010), las campiñas cerealistas (Baraja, 2010), los paisajes de viñedos (Molinero, 2010) o los paisajes del 
olivar (Guzmán Álvarez, 2005a; Loumou \& Giourga, 2003). Según Delgado et al. (2013: 269) el olivar constituye una constante en los variados paisajes mediterráneos y su dominante arbórea, perennifolia, relativamente abierta y con variopinto sotobosque herbáceo y florístico, impone una imagen viva, de tonos estacionalmente cambiantes. Se entiende aquí por paisaje el resultado, en términos visuales y estéticos, del impacto interactivo, sobre el territorio, de los factores climáticos, de relieve, agua, suelo, flora y fauna naturales y las acciones antrópicas. El resultado de dicha interacción es, en definitiva, una disposición espacial específica de los agroecosistemas, que es una característica de cada territorio, constituyendo su dimensión más perceptible (Sayadi y Calatrava, 2001: 27). En el caso que nos ocupa, ¿cuándo devienen paisajes los territorios del olivar? Cuando media la emoción y se produce la interacción necesaria entre el sujeto que percibe y el objeto percibido (Guzmán Álvarez y Zoido, 2013: 84).

La consideración a la hora de determinar la participación de los sistemas agrarios, y el caso del olivar no es una excepción, en procesos de desarrollo rural o regional, de características distintas a la productividad y a la mera rentabilidad financiera, han sido objeto de diversos estudios debido a la creciente sensibilidad que la sociedad muestra por la consideración y valorización de determinadas externalidades, particularmente las de naturaleza medioambiental. En general, las nuevas funciones que se le reconocen a los mencionados sistemas están ligadas, según Allaire \& Boyer (1995: 276) y Allaire (1996: 101) a la aparición de nuevos productos, nuevos derechos y nuevos bienes públicos, en los que los sistemas agrarios intervienen directamente o indirectamente. Características como la sustentabilidad (Painter, 1991; Sevilla \& Dent, 1994; Barnett et al., 1994; Cadenas, 1995; Daly y Gayo, 1995; Calatrava y Sayadi, 2001), la calidad productiva (FAO,1992; Casabianca, 1993; Guillou, 1994), el equilibrio, la eficiencia, el valor económico total (Naredo y Campos, 1980; Pearce \& Turner, 1990; Campos, 1994; Campos et al., 1996), el nivel de interacción medioambiental (AItieri, 1993) y el sociocultural (Calatrava \& González, 1992; Sánchez de Puerta, 1996) de estos sistemas deberían ser tenidos en cuenta a la hora de valorar su funcionamiento actual y las posibles transformaciones, y determinar así su idoneidad en marcos correspondientes a procesos de desarrollo rurales y/o regionales. Por su parte, algunos estudios analizan, además del aspecto estético de los sistemas agrarios, las actividades económicas terciarias que generan o en las que participan, tales como el turismo rural (Bazin, 1993; Calatrava y Ruiz, 1993; Rodríguez y Gómez, 1996; Calatrava y Sayadi, 1997; Sayadi y Calatrava, 1997) o el oleoturismo (Matos, 2006; Ruiz, 2011; Duarte Alonso \& Northcote, 2010). Por último, otros trabajos muestran, dentro de la filosofía de aprovechamiento integral de recursos endógenos en el ámbito rural, la importancia del turismo rural en general (Calatrava, 1983; Faggion, 1983; Grolleau, 1987; Lane, 1994), o del oleoturismo, en particular (Ruiz et al., 2011; Molina et al., 2011; Millán et al., 2010), como actividades que complementan aquellas consideradas como básicas para la economía local. En definitiva, todo apunta hacia el concepto de multifuncionalidad de los sistemas agrarios ${ }^{5}$.

Por otra parte, el sector turístico se ha convertido en uno de los principales motores del desarrollo socioeconómico de un elevado número de países y regiones. De hecho, según las previsiones de la Organización Mundial del Turismo, se espera que para el año 2020 el turismo sea la primera actividad económica mundial, llegándose a alcanzar una cifra cercana a 1.6 billón de llegadas internacionales (Organización Mundial del Turismo, 2011: 9).

En el ámbito internacional este sector está sujeto a continuos cambios debido al creciente número de factores que intervienen en su conformación como motor económico independiente. El modelo turístico tradicional (turismo estacional de masas) se está transformado, dando lugar a múltiples realidades turísticas caracterizadas por la diversidad de segmentos y productos. En este escenario

\footnotetext{
5 La multifuncionalidad representa el hecho de que estos sistemas realizan en el espacio rural que ocupan, y para la comunidad local que los desarrolla, funciones de diversa índole que van más allá de su papel productivo de alimentos y materias primas vegetales y animales, dando lugar a otros bienes y servicios, algunos de los cuales suelen ser bienes públicos.
} 
de complejidad y continuas transformaciones se encuentra también inmersa la región andaluza, un destino que cuenta con gran capacidad de atracción. La Comunidad Autónoma Andaluza, situada en el sur de España, se caracteriza por ser un espacio turístico, de gran singularidad, en el que conviven diferentes grados de desarrollo y modelos de explotación turística con una fuerte presencia de la propuesta de sol y playa. La región está vinculada fuertemente a dicha modalidad turística debido, principalmente, a su posición geográfica privilegiada y a la climatología favorable de la que disfruta gran parte del año (Castillo, 2011: 13). Desde hace años los organismos públicos y privados vienen trabajando en la elaboración de planes de fomento del turismo, entre los que destaca el III Plan de Calidad Turística de Andalucía 2014-2016, el cual tiene como objetivo general contribuir al desarrollo e impulso de un nuevo modelo de desarrollo turístico basado en criterios de calidad, accesibilidad y sostenibilidad en los destinos turísticos andaluces, promoviendo, al mismo tiempo, la innovación en la gestión turística y el apoyo a sectores turísticos poco consolidados que posibiliten la diferenciación y el liderazgo de Andalucía como destino de referencia internacional. Por tanto, Andalucía no ha permanecido al margen del proceso de evolución de este sector, y aunque se sigue relacionando la oferta turística andaluza con el segmento más clásico, desde hace unos años han surgido otras propuestas alternativas: el turismo deportivo; el turismo de aventura; el turismo de naturaleza; el turismo cultural; el turismo urbano; el turismo rural; el turismo de cruceros; el turismo de reuniones; el turismo gastronómico, el turismo industrial, el turismo idiomático y el turismo de salud y belleza.

España es un país en el que la agricultura ha ido reduciendo su aportación al PIB nacional en las últimas décadas ${ }^{6}$. No obstante, el sector del aceite de oliva aún representa un importante aporte de riqueza, no solo económica, sino también cultural y de identidad de

\footnotetext{
6 En el año 1980 la participación del sector agrario en el PIB español era del 7,2\%. Sin embargo, en el año 2013 ha sido solo del 2,6\% (Elaboración propia a partir de datos de Contabilidad Nacional del Instituto Nacional de Estadística).
}

cara al exterior. La necesidad del campo español en general, y del andaluz en particular, de encontrar nuevos canales de diversificación económica ha planteado la posibilidad, considerando las tendencias turísticas más recientes, de aprovechar un segmento hasta ahora poco explotado, el que corresponde a las prácticas y actividades productivas y consuntivas ligadas al aceite de oliva (el oleoturismo considerado como una actividad de turismo rural, de turismo industrial o de turismo gastronómico).

Por lo tanto, aunque la producción agropecuaria continúa siendo la principal actividad económica en el medio rural andaluz, no puede seguir considerándose como el único pilar sobre el cual sustentar su desarrollo. El desarrollo rural no depende solo del sector agrario. Se fomentarán otras formas de actividad económica que contribuyen a mantener la población rural y consolidar la economía de las regiones rurales (Objetive $n^{\circ} 3$ of the Communication of the Commission to the Council. Commission of the European Communities. June, 1991), (Consejería de Agricultura y Pesca, Ley del Olivar. Documento de reflexión. Grupo de Ordenación del Territorio y Desarrollo Rural, 2009) (Ley del Olivar de Andalucía, 2011) (Foro Europeo de las Regiones Olivareras, 2012).

En el contexto actual se refuerza el papel de los recursos patrimoniales, vinculados a un territorio, de carácter único e irrepetible. Este sería el caso de los paisajes del olivar en Andalucía, donde el territorio pasa de ser considerado un agente pasivo, o mero soporte físico de los procesos de desarrollo, a constituirse en agente activo de los mismos. La posibilidad de convertir algunos territorios en escenarios turísticos, facilitadores del desarrollo, va a propiciar que muchas comarcas rurales en Andalucía consideren la actividad turística casi como la única alternativa para conjurar el marasmo económico y el colapso demográfico, en especial en zonas de montaña, de difícil acceso o con problemas para generar procesos de desarrollo. Para bastantes zonas de la comunidad andaluza resulta fundamental aprovechar aquellos recursos territoriales, sobre todo los relacionados con la actividad turística, que puedan contribuir al desarrollo de las mismas. 


\section{Los paisajes del olivar en Andalucía}

En España, los olivares se encuentran repartidos por casi todo su territorio nacional y ocupan una gran diversidad de parajes y emplazamientos, caracterizando el paisaje de numerosas zonas y comarcas (Figura $\mathrm{N}^{\circ}$ 1). En ninguna otra parte de Europa hay una concentración similar de una única especie arbórea cultivada en un área tan extensa.

Figura $N^{0} 1$

Porcentaje de superficie cultivada de olivares

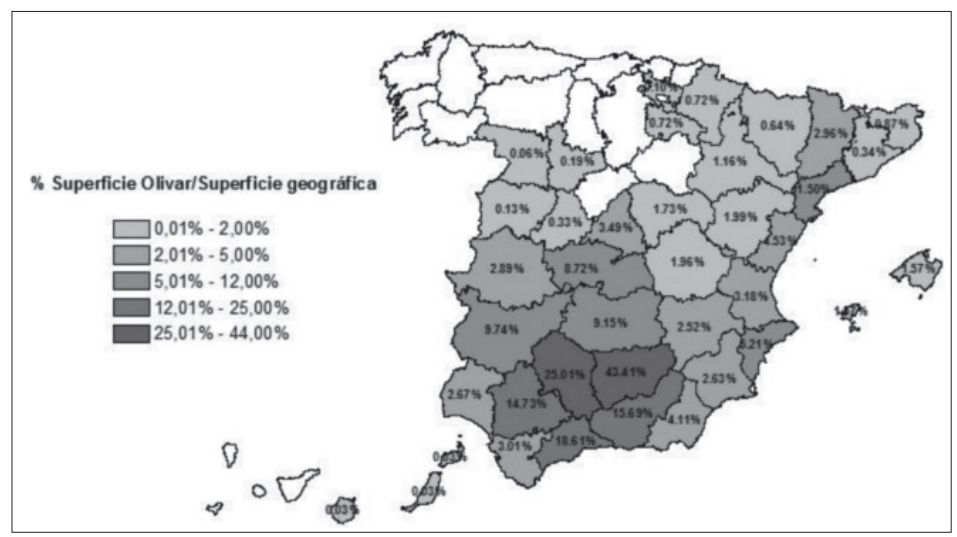

Fuente: Encuesta sobre superficies y rendimientos de cultivos, 2012.

Figura $N^{\circ} 2$

Porcentaje de superficie ocupada por olivares sobre superficie de tierra cultivada

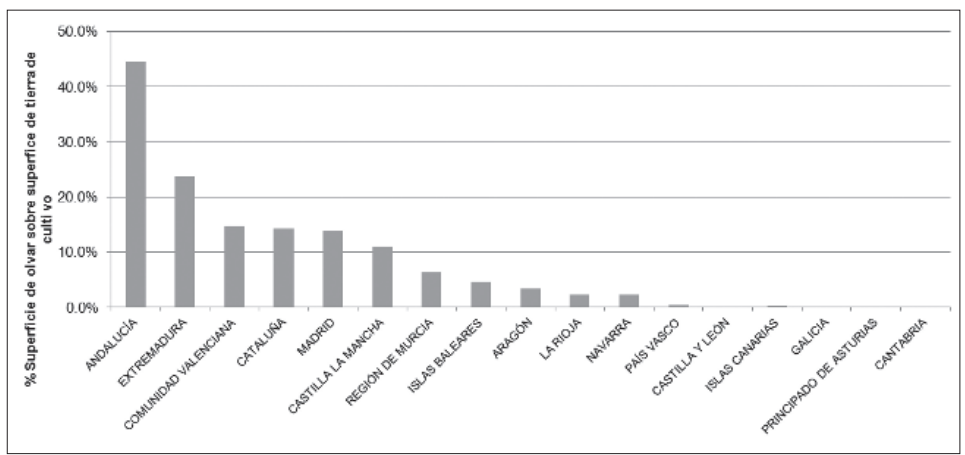

Fuente: Encuesta sobre superficies y rendimientos de cultivos, 2012.

Considerando la superficie de olivar, respecto a la superficie total de cultivo por comunidad autónoma, se tiene el resultado que se muestra en la Figura $N^{\circ} 2$.

Como se puede apreciar en esta Figura, el olivar es un elemento configurador de Andalucía y forma parte de su capital territorial ${ }^{7}$.

7 Se refiere a las capacidades o potencial específico que caracterizan a una región y la diferencian de
Si algo caracteriza al cultivo del olivar en Andalucía es su gran diversidad en muchos aspectos. Este cultivo presenta en la región una enorme diversidad estructural, agronómica y productiva que persiste, aunque en menor medida, en cualquier ámbito territorial con-

otras. El capital territorial está configurado por una amplia gama de factores socioculturales (capital social), geoambientales, económicos, institucionales y factores intangibles (entorno creativo e innovador). 
siderado (provincial, comarcal o municipal). Su importancia histórica y cultural obliga a considerarlo, al menos a determinados olivares, como algo más que un cultivo destinado a la producción de aceite. Es tanta la historia asociada a ellos que se les puede considerar como auténticos paisajes culturales, como parte de un legado secular. Y esta funcionalidad, histórico-cultural, debería ser tenida en cuenta y valorada (Guzmán, 2005a: 14). La continua expansión histórica de este sistema agrícola ha marcado el paisaje, la economía y la cultura de numerosas comarcas de la comunidad andaluza. En muchas zonas la extensión territorial de los olivares y su carácter de monocultivo ha condicionado el modo de vida de una parte importante de la población (Unidad de Prospectiva de la Consejería de Agricultura y Pesca de la Junta de Andalucía, 2002: 6).

En la actualidad Andalucía es considerada la mayor región olivarera en el mundo, representando la producción de aceite de oliva una de las principales actividades económicas de la región. En el año 2013 la superficie de olivar andaluz alcanzó las 1.550.218 ha, siendo 169.459 las explotaciones de olivar y 2.240 millones de euros el valor de producción en la campaña 2013-2014. Además, este cultivo es uno de los que más empleos generan por unidad de superficie, lo que le ha dado el apelativo de "cultivo muy social". Así, según el censo agrario, el olivar genera en Andalucía en torno al 32 por ciento de la mano de obra de todo el sector agrícola y ganadero.

En todo caso, cabe destacar que el cultivo del olivar es, en términos relativos, la actividad más rentable económicamente y con mejor desempeño social, al menos si se compara con otros usos alternativos (agrarios o forestales) del territorio. De hecho, cualquier circunstancia que promueva el abandono del cultivo generaría unos efectos socioeconómicos negativos de importancia: pérdida de renta de los agricultores, disminución de la riqueza del conjunto de la población e incremento de la tasa de desempleo.

Por último, Gómez-Limón y Arriaza (2011: 18) destacan la importancia medioambiental del cultivo. El mismo suele ser, en general, bastante extensivo y no tan agresivo para el medio ambiente como en el caso de otras producciones agrarias. No en vano, el olivar es uno de los cultivos, junto con los cítricos, cuya conversión a la agricultura ecológica resulta más sencilla. En esta misma línea cabe señalar cómo tradicionalmente el olivar andaluz ha venido soportando una rica biodiversidad, siendo un claro ejemplo de sistema agrario de alto valor natural (Baldock et al., 1993: 56; Beaufoy et al., 1994: 24; Bignal y McCracken, 2000: 155). Tal circunstancia ha sido posible al ser sistemas donde históricamente se han conjugado una baja intensidad productiva (escaso uso de agroquímicos), la presencia de olivos viejos asociados a vegetación herbácea seminatural durante buena parte del año y su localización en zonas con usos del suelo variados (mosaicos).

Las provincias de Jaén, Córdoba, Granada, Málaga y Sevilla (Figura № 3) conforman el denominado "eje del olivar", siendo las dos primeras las que acaparan casi el $60 \%$ del olivar andaluz.

En la provincia de Jaén, el olivar alcanza el $90 \%$ de ocupación de la superficie agrícola, presentándose casos, en algunas comarcas y municipios, en los que la presencia de otros cultivos es testimonial o ha desaparecido definitivamente (Sánchez et al., 2011: 205).

Sin embargo, los paisajes del olivar andaluz, globalmente considerados, presentan una enorme diversidad estructural, agronómica y productiva que persiste, aunque en diferente grado, en cualquier ámbito territorial considerado (provincial, comarcal, municipal). Guzmán (2005b), mediante el método de superposición cartográfica, auxiliado por cartografía tanto analógica como digital, ha llevado a cabo un contraste multivariante que le ha permitido elaborar una clasificación territorial del olivar en Andalucía. De esta manera, es posible distinguir diversos tipos de paisajes del olivar andaluz en función de las características del medio físico (Figura $N^{\circ}$ 4): olivar de campiña, olivar sobre colinas sedimentarias, olivar sobre cerros sedimentarios, olivar sobre llanuras y vertientes metamórficas, olivar de lomas y llanuras sobre depósitos aluviales, olivar de Ilanura sobre depósitos diluviales, olivar sobre planicie de origen endógeno, olivar de vegas interiores semiáridas, olivar en mosaico de cuencas in- 
Figura $N^{\circ} 3$

Hectáreas de cultivo de olivar en Andalucía

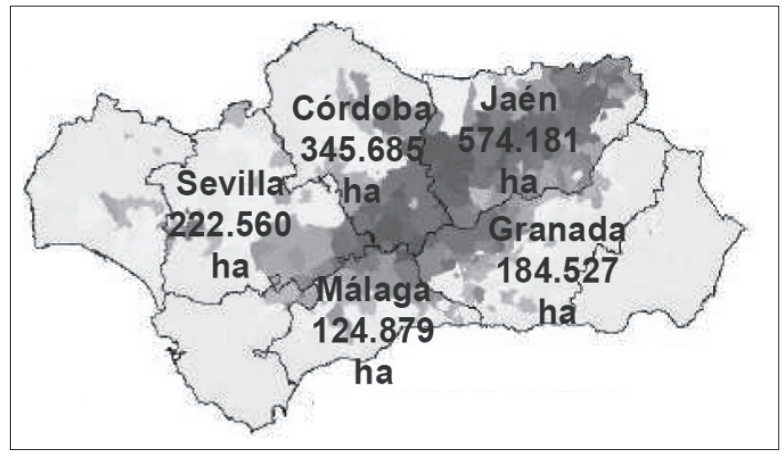

Fuente: Aforo de olivar. Campaña 2013-2014, 2013

Figura $\mathrm{N}^{\circ} 4$

Tipos de paisajes del olivar andaluz

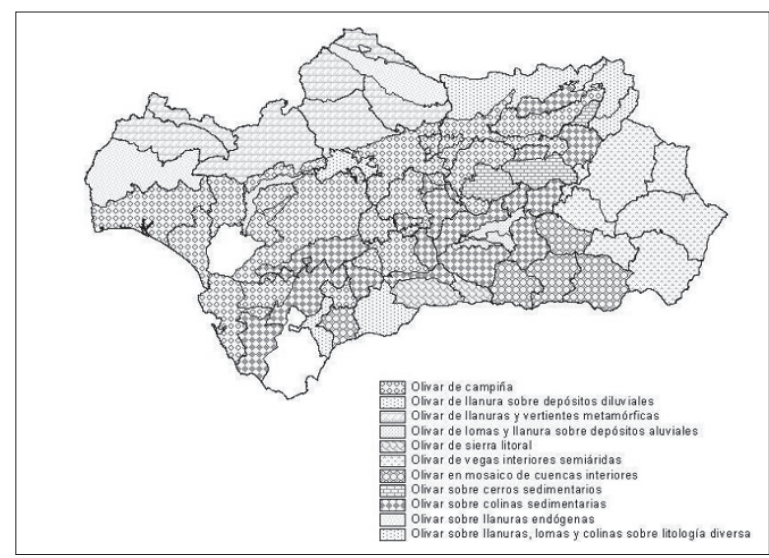

Fuente: Guzmán (2005b).

teriores, olivar sobre Ilanuras, lomas y colinas de litología variada, y olivar de sierra litoral.

Por lo tanto, no queda otra alternativa que reconocer los matices del cultivo del olivo, algunos muy ostensibles y determinantes, que a menudo reflejan profundas diferencias agronómicas y territoriales. A pesar de esta diversidad, a gran parte de estos paisajes se les reconoce una serie de valores comunes asociados (carácter multifuncional de los paisajes del olivar andaluz) (Nogué y Sala, 2008: 89-90):

- Valores estéticos: la capacidad que tiene un paisaje para transmitir un determinado sentimiento de belleza. Los valores pai- sajísticos forman un conjunto indisociable con otros elementos de índole cultural. En este caso se trata de zonas o ámbitos olivareros con destacados valores plásticos, de belleza visual.

- Valores ecológicos: factores o elementos que determinan la calidad del medio natural. Un olivar no está formado únicamente por los olivos, sino que siempre tiene una serie de recursos asociados a él como el suelo, el agua, otras plantas y la fauna que habita en el mismo. En este sentido, el cultivo del olivar destaca por su adaptación al clima mediterráneo, su eficiencia en el empleo del agua y su ocupación, por lo general, de terrenos no aptos para otros cultivos, que constituyen 
muchas veces conjuntos con alto valor medioambiental y paisajístico, refugio de flora y fauna singulares.

- Valores productivos: la capacidad de un paisaje de proporcionar beneficios económicos, convirtiendo sus elementos en recursos.

- Valores históricos: los olivares mantienen vivo un legado cultural centenario que refleja las huellas (impronta) más relevantes que los diferentes pueblos han dejado en este paisaje a lo largo de la historia.

- Valores de uso social: la utilización que hace un individuo o un determinado colectivo de un paisaje. Los olivares son paisajes agrarios que, a diferencia de los espacios modelados por la naturaleza (riscos, cárcavas, oquedades) o diseñados intencionalmente por el hombre (parques y jardines), aúnan de manera indisoluble fisonomía y funcionalidad.

- Valores simbólicos y de identidad: corresponde a la identificación que un determinado colectivo hace de un paisaje.

Todos estos valores son componentes de este auténtico capital territorial de Andalucía que, aprovechado de manera conveniente, pueden contribuir al desarrollo rural y regional en un sentido amplio.

\section{El oleoturismo en Andalucía}

Se considera como oleoturista aquella persona que realiza un desplazamiento en su tiempo de ocio, a un lugar distinto al de su residencia habitual, para profundizar en el conocimiento de la cultura del olivo y del aceite, no teniendo que alojarse en un lugar específico, y que realiza alguna/as de las siguientes actividades (turismo a la carta):

- Visita a almazaras ${ }^{8}$ (en Andalucía existen más de 800), a viejos molinos aceiteros, a antiguas haciendas (cortijos), a oleotecas y tiendas especializadas o a museos del aceite. Con esta práctica se puede conocer el proceso de producción específico del aceite de oliva.

\footnotetext{
8 Una almazara es el lugar en el que se obtiene el aceite de oliva, a partir de las aceitunas, mediante un proceso en el que interviene maquinaria diversa.
}

- Visita a la explotación agraria y contemplación de la estética de los paisajes del olivar. Dentro de este apartado, como actividad singular, se pueden destacar también las visitas para contemplar ejemplares monumentales que es posible encontrar en algunas zonas productoras.

- Participación en fiestas del aceite que se celebran en determinadas localidades productoras.

- Conocimiento de las diferentes tradiciones populares vinculadas a la cultura del olivo.

- Participación en actividades gastronómicas con el aceite de oliva como protagonista.

- Recorrido de las rutas ${ }^{9}$ vinculadas a las 12 Denominaciones de Origen ${ }^{10}$ del aceite de oliva existentes en algunas provincias de Andalucía: Cádiz (Sierra de Cádiz), Córdoba (Lucena, Baena, Montoro-Adamuz y Priego de Córdoba), Granada (Montes de Granada y Poniente de Granada), Jaén (Sierra de Segura, Sierra de Cazorla y Sierra Mágina), Málaga (Antequera) y Sevilla (Estepa).

- Asistencia a ferias comerciales relacionadas con la producción del aceite de oliva.

- Conocimiento de las características de otras industrias relacionadas con el olivo y el aceite de oliva (cosmética, conserveras, artesanía de madera, aceitunas aderezadas, etc.).

Como ya se indicó con anterioridad, el olivar es un cultivo de enorme importancia social en Andalucía. Para diversas comarcas andaluzas el olivar es la única fuente de ingresos directos e indirectos de la población, siendo la actividad económica principal en más de 300 municipios andaluces

\footnotetext{
9 Se trata de itinerarios que permiten conocer y disfrutar el proceso productivo agropecuario, industrial y la degustación de la cocina regional, expresiones de la identidad cultural de cada zona. Se organizan en torno a un producto clave, el aceite de oliva, en este caso, que las caracteriza y les otorga el nombre.

${ }^{10}$ Es un tipo de indicación geográfica, aplicada a un producto agrícola o alimenticio, cuya calidad o características se deben fundamentalmente al medio geográfico en el que se produce, transforma y elabora. Permite distinguir a los productos, de características exclusivas y que se han obtenido en una determinada zona, de los de otras zonas que no presentan tales singularidades.
} 
y para 250.000 familias. Precisamente esa gran dependencia del cultivo del olivar, que muestran muchos municipios en Andalucía, provoca fuertes incertidumbres para muchos productores respecto a la percepción de rentas. Ello es debido a que la cantidad y calidad de la producción anual no se conocen con certeza. Esta incertidumbre está vinculada a determinados elementos incontrolables, como el clima, que condicionan fuertemente la producción agrícola. Los efectos de estos factores incontrolables se agudizan por la estacionalidad de la producción del olivar que concentra, en pocos meses, el trabajo y las rentas de todo el año. Para hacer frente a la variabilidad de la producción y, por tanto, de las rentas de las personas dedicadas al cultivo del olivo, en determinadas comarcas se ha comenzado a ofertar la práctica del oleoturismo, como actividad complementaria vinculada a la cultura del olivo, generándose una simbiosis entre dos sectores, el agrícola y el turístico, representado el desarrollo de esta modalidad la utilización, como reclamo turístico, de todos aquellos aspectos vinculados a dicha cultura (Figura $N^{0} 5$ ).

Figura $\mathrm{N}^{\circ} 5$

Oleoturismo: el turismo relacionado con la cultura del olivo

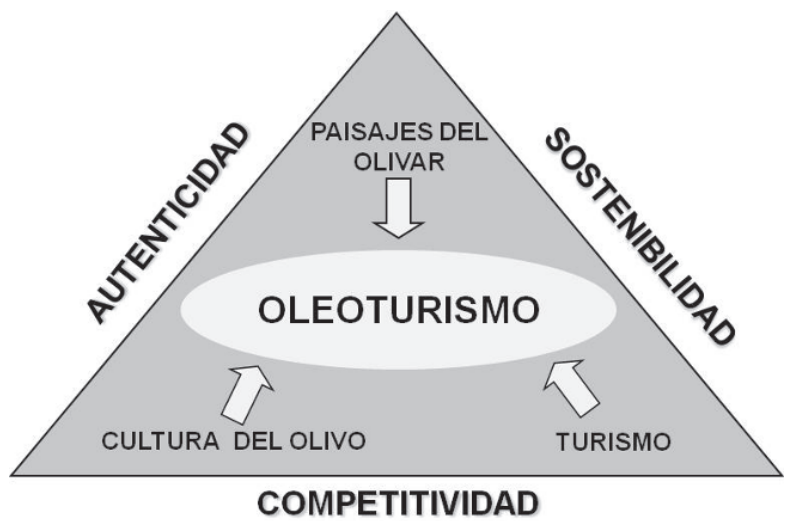

Fuente: Elaboración propia.

Desde un planteamiento pluridimensional del concepto del desarrollo, que no reduce su significado al ámbito estrictamente económico, sino que se orienta hacia la consecución de objetivos económicos, sociales, medioambientales y culturales, existen suficientes argumentos para considerar a los paisajes del olivar como un recurso clave para potenciar el desarrollo rural en determinadas comarcas de Andalucía ${ }^{11}$. La diversidad de estos paisajes ofrece un marco idóneo para el desarrollo

\footnotetext{
11 Una de las vías más frecuentes para poner en valor los recursos patrimoniales es orientarlos hacia el ocio y el turismo. En este caso, se trata de convertir en producto turístico el patrimonio relacionado con la cultura del olivo en Andalucía, como contribución al desarrollo regional. Además, no se debe obviar que los productos turísticos que ponen en valor el patrimonio tienen una fuerte componente territorial.
}

de actividades de oleoturismo: la contemplación de la belleza de los paisajes y el disfrute de las sensaciones de paz y tranquilidad vinculadas a ellos, las visitas a las almazaras, las catas, así como el estudio de la cultura y la historia del aceite. Muchas de estas actividades pueden generar empleo y renta, facilitando la fijación de la población en el ámbito rural en el que se realizan. En definitiva, el oleoturismo puede resultar una contribución más al desarrollo de la Comunidad Andaluza.

¿Cuáles son las características que presenta esta modalidad turística en Andalucía? La especificidad de esta práctica hace que sea bastante reducido el material de investigación disponible con relación a la misma, y más teniendo en cuenta que se trata de una tipología relativamente reciente. Por tal motivo, y con la intención de realizar un diagnóstico de su situación actual y de la del patrimonio te- 
rritorial y cultural vinculado a ella, a lo largo del año 2013 se realizaron diversas entrevis$\operatorname{tas}^{12}$ a presidentes de los Consejos Reguladores $^{13}$ de las Denominaciones de Origen del aceite de oliva de Andalucía, a miembros de Patronatos de Turismo ${ }^{14}$ de pueblos en los que el cultivo del olivo es especialmente representativo, a diversos gerentes de almazaras, algunas de las cuales no eran visitadas por turistas y otras en las que sí se realizaba dicha actividad, así como a responsables de empresas que forman parte de las rutas alimentarias dedicadas al aceite de oliva (restaurantes, hoteles, tiendas de productos del aceite, etc.). En definitiva, se ha tratado de desvelar la percepción que agentes relevantes, relacionados al sector del aceite de oliva, tienen sobre la realidad de esta modalidad turística y sobre la del patrimonio territorial y cultural que la sustenta. Con la información obtenida se ha realizado un análisis DAFO (SWOT analysis). El propósito último es aprovechar la información suministrada por dicho análisis para proponer actuaciones que hagan posible que el oleoturismo contribuya a preservar los paisajes del olivar y a promover el desarrollo rural y regional de Andalucía.

\section{Análisis DAFO}

\section{Debilidades}

- Aunque los mecanismos de apoyo público a este cultivo han ido desapareciendo o

\footnotetext{
12 De enero a diciembre del año 2013 se realizaron 88 encuestas. El cuestionario incorporaba 22 preguntas, agrupadas en tres bloques distintos: $1^{\circ}$ número de trabajadores y volumen productivo y de facturación de las empresas, $2^{\circ}$ implicación de los diferentes agentes encuestados en actividades relacionadas con el oleoturismo, $3^{\circ}$ acciones impulsadas por estos agentes para fomentar y potenciar el desarrollo del oleoturismo. El error muestral de la encuesta era del $\pm 4,6 \%$.

13 Son los organismos encargados de regular y normalizar la actividad de los agentes adscritos a una Denominación de Origen, así como los responsables de velar por el cumplimiento efectivo de las normas de actuación en él establecidas.

${ }^{14}$ Se trata de organismos públicos (dependientes de administraciones públicas como Ayuntamientos o Diputaciones Provinciales) o público-privados, cuya actividad se centra fundamentalmente en estructurar y planificar la oferta turística de una ciudad o de una provincia, además de promover el desarrollo turístico de la misma.
}

perdiendo importancia, en Andalucía es perfectamente reconocible un modelo de olivar creado por la Política Agraria Comunitaria (PAC) ${ }^{15}$ y fuertemente subvencionado por dicha política (Sánchez et al., 2011: 206). Así las subvenciones provenientes de la misma representan más de un tercio de los ingresos de las explotaciones del olivar, porcentaje superior a la media del sector agrario.

- El riesgo de disminución y reconversión de las ayudas agrarias provenientes de la PAC (Unión Europea) a partir de 2013, unido a la experiencia acumulada en otros países productores (Túnez, Marruecos o Argentina), ha determinado la introducción de modelos de olivar intensivo o superintensivo (hiperintensivo), con notables diferencias respecto al olivar tradicional ${ }^{16}$, y muy demandante de fertilizantes y fitosanitarios. De esta manera, se persigue ser competitivos incrementando, aún más, la producción y reduciendo los costes de la mano de obra. Estos cambios han provocado externalidades medioambientales muy graves. La erosión del suelo por destrucción de la vegetación espontánea (pérdida de suelo fértil), la sobreexplotación y contaminación de los recursos hídricos, la pérdida de biodiversidad y la banalización de los paisajes tradicionales son muy acusados, a pesar de algunas ini-

\footnotetext{
15 España se incorpora a la Comunidad Económica Europea en 1986 y comienzan a llegar, después de un período de transición, las ventajas contempladas en la Organización Común de Mercado de las grasas vegetales de 1966. La existencia de un precio de intervención y las ayudas a la producción y al consumo de aceite de oliva, así como la protección aduanera y las restituciones a la exportación propiciaron, como en otras parcelas de la PAC, una verdadera fiebre productivista permanentemente estimulada y protegida.

16 El olivar andaluz es predominantemente minifundista (el $80 \%$ de las explotaciones tiene menos de 5 ha), con una presencia destacada de la agricultura a tiempo parcial. Una parte considerable de los olivares se extiende por suelos con importantes limitaciones para el cultivo e incluso en terrenos que no tienen una clara vocación agrícola, como consecuencia de las elevadas pendientes. Está constituido mayoritariamente por olivos adultos de secano con un sistema de cultivo tradicional, aunque con un avance muy destacado del regadío durante las dos últimas décadas, que afecta sobre todo a las nuevas plantaciones que responden, básicamente, al modelo de olivar intensivo.
} 
ciativas, vinculadas a la propia PAC, con el propósito de reducir esas externalidades ambientales negativas.

- Estacionalidad de la campaña de recolección de la aceituna (meses de noviembre y diciembre).

- Las actividades relacionadas con el oleoturismo en Andalucía se caracterizan por su estacionalidad, presentándose picos de actividad en Navidad (diciembre-enero), Semana Santa (marzo-abril), verano (julioagosto) y algunos días festivos en el ámbito regional y nacional.

- En algunas épocas del año la oferta de plazas hoteleras (casas rurales y hoteles rurales) es insuficiente, no satisfaciendo la demanda existente que se dirige hacia otras zonas y experiencias.

- La inadecuada capacitación de trabajadores y empresarios del sector. Generalmente se incorporan personas de las zonas rurales con dedicación previa a actividades agrícolas, ganaderas o de otro tipo, que no han tenido relación alguna con la actividad turística y, por lo tanto, sin ningún tipo de formación específica. Este déficit formativo afecta negativamente a la percepción de calidad de los servicios por parte de clientes cada vez más exigentes.

- La falta de conciencia, en gran parte de la población de las zonas en las que estas actividades se realizan, de que el oleoturismo puede representar realmente una fuente de ingresos complementarios a los obtenidos con la actividad agraria.

- Destaca la ausencia de una visión estratégica que integre transversalmente cultivo del olivo, desarrollo sostenible y actividad turística, para fomentar la sostenibilidad del medio ambiente y la generación de riqueza y empleo. Suele existir poca coordinación entre las acciones que impulsa el sector turístico y las desarrolladas por el resto de sectores de actividad.

- Al igual que en otros sectores de actividad, faltan emprendedores.

- Falta de experiencia en la comercialización (el marketing) de esta modalidad turística. El resultado es la oferta de un "producto desestructurado", el cual tiene bastante limitada su promoción, dado que existen problemas para acceder a los canales tradicionales de distribución turística. En este mismo sentido, el grado de innovación tecnológica en este segmento es muy bajo, lo que dificulta aún más la promoción de la oferta.

- El acceso a la financiación ajena, por parte de las pequeñas y las medianas empresas del sector, es muy limitado.

- Pérdida progresiva de actividades y saberes tradicionales relacionados con el proceso productivo del aceite de oliva.

- Incremento del gasto vinculado a tareas de mantenimiento de las almazaras en las que se realizan actividades relacionadas con el oleoturismo.

- Ausencia de relevo generacional y consiguiente reducción paulatina de los agricultores profesionales.

\section{Amenazas}

- Existencia de un componente estacional importante, para la realización de determinadas actividades turísticas, al depender de la realización de tareas y periodos correspondientes a la recogida de aceituna y la producción de aceite.

- La persistencia, en algunas zonas, de vertederos incontrolados que afectan negativamente a los paisajes del olivar y que hacen inviable cualquier actividad turística relacionada con ellos.

- La crisis económica reduce las visitas y el gasto de los turistas.

- Todavía hay personas que consideran al oleoturismo como una modalidad reservada para aquellos segmentos sociales con rentas más altas. En definitiva, turismo de lujo.

- Excesiva mercantilización de algunas manifestaciones culturales vinculadas al aceite de oliva.

- En determinados casos existe la posibilidad de que, debido al desarrollo de esta actividad turística, se produzca la pérdida de identidad y de algunos valores autóctonos, además de cambios irreversibles en la forma de vida local.

- Motivado por diversos factores y circunstancias, deterioro del entorno natural y creciente descapitalización de los paisajes del olivar: contaminación visual, estandarización, banalización, simplificación y desarticulación.

- Unos precios de mercado del aceite (en origen) por debajo del nivel mínimo que hace viables a un gran número de explotaciones. Durante los últimos años, el consumo del aceite de oliva ha experimenta- 
do un repunte más que considerable. Sin embargo, estas condiciones de mercado tan favorables no están teniendo su reflejo en los precios pagados a los agricultores. El precio del aceite de oliva virgen en origen ha caído muy por debajo de unos costes de producción en aumento. De este modo, el esfuerzo inversor realizado por productores y almazaras, para conseguir una materia prima de máxima calidad, no se está viendo recompensado y eso ya está pasando factura en términos de renta y empleo en zonas productoras. Esta problemática no afecta solo a los olivareros, sino al conjunto de la población de muchas zonas y comarcas del medio rural andaluz en las que esta actividad es la principal generadora de riqueza y empleo.

- Los sistemas intensivos y/o superintensivos terminarán marginalizando a las explotaciones de olivar tradicionales (dos tercios de la superficie total de olivar en Andalucía), fundamentalmente en zonas de montaña.

- Las actividades turísticas provocan la subida de los precios en las zonas en las que se llevan a cabo.

- En algunas zonas, expansión urbanística desordenada y sin planeamiento, con escaso o nulo respeto por los paisajes del olivar.

- Despoblamiento de las áreas de montaña y pérdida acelerada de patrimonio etnológico, tanto material como inmaterial.

- La mayor dependencia de las subvenciones $(53 \%$ por ciento del total del pago único recibido) hace del olivar andaluz uno de los sectores más amenazados por la próxima reforma de la PAC (sexenio 2014-2020).

Lo que pueda suceder cuando las ayudas de la Unión Europea pierdan la importancia que ahora tienen. Los distintos programas desarrollados han propiciado que Andalucía recibiese, cada año, una cantidad importante de recursos, de los que la cuantía más importante se destina a la agricultura y al desarrollo rural. El nuevo programa de ayudas para 2014-2020 contempla para la región alrededor de 1.906 millones de euros al año para la agricultura y el desarrollo rural. En este nuevo marco se va a producir un descenso de las subvenciones al pasar la comunidad andaluza del grupo de regiones menos desarrolladas a la condición de región en transición.
Con el desacoplamiento de las ayudas a la producción, los oleicultores no estarán obligados a seguir produciendo para recibir la subvención, por lo cual aquellos olivares menos productivos, generalmente en zonas de montaña, presentan un alto riesgo de abandono. Teniendo en cuenta que las zonas en las que se encuentran estos olivares suelen presentar un alto valor medioambiental, en muchos casos adyacentes a espacios naturales protegidos, su abandono puede poner en riesgo el equilibrio ecológico de algunas zonas.

Por otro lado, se prevé que la mencionada reforma determine que el olivar tradicional andaluz pase a ser poco rentable, y siempre gracias a la percepción de las ayudas, pues de otro modo esta modalidad, la de mayor implantación en Andalucía, dejaría de ser económicamente viable. Por lo tanto, este proceso de cambio abre una nueva etapa en la dinámica de los paisajes del olivar andaluces y la no consideración de la multifuncionalidad de estos sistemas agrarios, a la hora del diseño de las políticas agrarias y de desarrollo rural, conllevará la desaparición de aquellas explotaciones que no alcancen un nivel mínimo de competitividad al considerarse, exclusivamente, su función productiva e ignorarse el resto de beneficios sociales asociados a dichos sistemas.

- El patrimonio arquitectónico tradicional (molinos de aceite, cortijos, etc.) sufre, en general, un acusado proceso de deterioro, afecta negativamente a la estética de los paisajes del olivar en la región.

\section{Fortalezas}

- Muchas de las actividades vinculadas al oleoturismo pueden contribuir a la conservación de las infraestructuras y la puesta en valor del patrimonio territorial y cultural relacionado con el aceite de oliva.

- En Andalucía existe una gran tradición turística y se ha acumulado una gran experiencia en el sector del turismo.

- En bastantes zonas se dispone de una buena red de comunicaciones, tanto carreteras como vía férrea, con el resto de la región y de España. 
- Las propuestas vinculadas al oleoturismo se pueden combinar fácilmente con otras modalidades turísticas presentes en las mismas zonas o comarcas: senderismo, actividad cinegética, turismo de naturaleza, turismo fotográfico y otras actividades que se pueden desarrollar en el medio rural.

- Andalucía cuenta con un importante patrimonio artístico y monumental. Ciudades y pueblos que ofrecen la posibilidad de visitar lugares históricos y/o conjuntos arquitectónicos (iglesias, casas señoriales, castillos, ermitas, puentes y museos).

- Durante todo el año se puede disfrutar en esta región de innumerables festejos y actividades culturales: carnavales en febrero; Semana Santa, fiesta de las cruces y romerías en primavera; veladas y verbenas durante los meses de verano y la celebración de ferias desde el mes de abril hasta finales de septiembre. Además, son muchas las actividades culturales que se llevan a cabo: teatros callejeros, festivales flamencos, concursos de pintura, fotografía, literarios, etc.

- Recuperación y reactivación de tradiciones locales y fiestas etnográficas basadas en el patrimonio cultural vinculado al olivar.

- Para realizar algunas actividades de oleoturismo no se exige unas condiciones climáticas favorables, lo cual hace factible que se puedan desarrollar durante bastantes meses a lo largo del año. Este hecho es de gran importancia tanto para la generación de empleo estable como para la generación menos estacional de rentas, circunstancias que no suelen darse en otras modalidades turísticas.

- La mayoría de la población que habita las zonas en las que se desarrollan actividades relacionadas con el oleoturismo se caracteriza por ser excelentes anfitriones y gente hospitalaria, abierta y acogedora.

- Se ha producido un aumento del asociacionismo en los municipios rurales. En este sentido, resaltar el protagonismo de las sociedades cooperativas olivareras y su estrecho vínculo con el desarrollo rural. La cooperativa es una fórmula idónea para el desarrollo del potencial endógeno de una zona.

\section{Oportunidades}

- La evidente saturación de los destinos tradicionales. Durante las últimas décadas se está evidenciando un cambio en los hábitos de los turistas. Aumenta así la demanda de nuevas experiencias y se atenúa la afluencia a los destinos clásicos. Es en esta búsqueda de la exclusividad cuando el patrimonio territorial y la cultura local cobran fuerza, convirtiendo su particularidad en un valor añadido: la cultura del aceite de oliva y todas sus manifestaciones patrimoniales.

Además, los hábitos y los valores de la población se transforman. En este proceso destaca la nueva sensibilidad que muestran muchas personas respecto a lo que se conoce como turismo rural sostenible. La urbanización, el régimen de vida y de trabajo en la ciudad, todo ello determina la necesidad y el deseo de amplios sectores de poblaciones urbanas de disfrutar de periodos de descanso fuera de su hábitat habitual. Se busca, sobre todo, realizar actividades en un entorno rural/natural y tradicional. En definitiva, el interés creciente por el patrimonio territorial y la cultura de las zonas rurales proveniente de las poblaciones urbanas que, por su condición, se han visto privadas de su conocimiento y disfrute. El entorno en el que se encuentran los olivares y la mayor parte de las almazaras de producción de aceite de oliva es el medio rural, lo que significa que el oleoturismo puede ser considerado como una práctica vinculada al turismo rural (Millán et al., 2014: 180). En definitiva, el medio rural es el marco habitual en el que se llevan a cabo las actividades más representativas de esta modalidad turística.

- Cada vez son más las personas que exigen alta calidad en la prestación de los servicios turísticos, no constituyendo el oleoturismo una excepción a este respecto. En particular, cada vez más turistas están dispuestas a pagar precios más elevados por productos autóctonos con denominación de origen. Conviene recordar que, actualmente, en Andalucía están reconocidas 12 Denominaciones de Origen del Aceite de Oliva.

- El oleoturismo contribuye a mejorar la imagen y las ventas del aceite de oliva.

- Se incrementa el número de consumidores que optan por los productos ecológicos, entre ellos, el aceite de oliva. En Andalucía se encuentran localizadas un número importante de empresas relacio- 
nadas con la producción de aceite de oliva ecológico.

- Los olivares son grandes extensiones que pueden capturar el $\mathrm{CO}_{2}$ atmosférico y almacenarlo en forma de carbono en la materia orgánica, lo que les confiere el carácter de sumideros de este gas de efecto invernadero. Además, se puede usar los restos de poda como biomasa, para producir energía.

Por otro lado, el olivar más tradicional, considerado como auténtico bosque mediterráneo, presenta un valor medioambiental indiscutible ya que contribuye a frenar el proceso de la erosión y el avance de la desertificación. Un paso firme en la expansión de los métodos ecológicos resulta fundamental, pues solo así se podrá seguir presentando a los olivareros como garantes de la conservación del medio ambiente y oferentes de productos de extrema calidad, lo cual justificará obviamente su reconocimiento social y, por ende, la valorización de su actividad por los mercados y por las instituciones públicas.

- El cambio del papel económico y social de la tradicional función productiva de alimentos de las zonas rurales, a través de una reestructuración de la estructura productiva, ofrece nuevas oportunidades de empleo para la población y un refuerzo de las funciones que la economía social viene desempeñando en zonas rurales. Así es posible el incremento de las rentas obtenidas por los habitantes de las zonas productoras de aceite de oliva, gracias al desarrollo de actividades complementarias relacionadas con la valorización y puesta en uso de recursos locales vinculados a la cultura del olivo. Conviene precisar que el oleoturismo no sería la fuente principal de ingresos, sino un complemento de renta. Esto contribuirá, además, a evitar los flujos migratorios hacia las zonas urbanas.

- La mayor conciencia existente en las comunidades rurales sobre el hecho de que el propio desarrollo no depende de factores exógenos, sino de la movilización de los recursos locales mediante la diversificación de las actividades económicas.

- Ha aumentado la sensibilidad de las administraciones públicas hacia el sector turístico en el medio rural, lo cual se ha traducido en un mayor apoyo, ofreciendo protección y recuperación del patrimonio histórico y otro tipo de iniciativas.

- Las políticas públicas de fomento del desarrollo de las zonas rurales. Las iniciativas comunitarias, como los programas Leader I, II y Leader +, Proder, Feder, Feader o la Ley del Olivar en Andalucía, han permitido implementar un conjunto de programas para el desarrollo rural con los objetivos de lograr el desarrollo endógeno y sostenido del medio rural, el fortalecimiento y diversificación de su economía, de las actividades en el ámbito agrario y ámbitos afines, el mantenimiento de la población, así como el aumento de las rentas y el bienestar de sus habitantes y el fomento de la conservación del espacio, del patrimonio rural y de los recursos naturales, existiendo en todos ellos mención al desarrollo de actividades de turismo rural. En este contexto, conviene resaltar el creciente interés de las administraciones públicas por el desarrollo de actividades de turismo rural sostenible. Dicho interés responde principalmente a la necesidad de buscar soluciones con las que los habitantes del medio rural puedan hacer frente a las dificultades económicas que tienen que afrontar.

- La última reforma de la PAC ha supuesto una apuesta decidida por un modelo dual de agricultura europea: por un lado se intenta orientar las producciones agrícolas hacia las demandas del mercado y, por otro, se pretende maximizar la provisión de externalidades positivas por parte del sector agrario. De esta forma, el apoyo a los agricultores se intenta justificar no tanto por la producción alimentaria sino por la provisión de servicios que se encuadran dentro del carácter multifuncional de la agricultura. Se amplía así el debate sobre la multifuncionalidad de la agricultura, para abordar la multifuncionalidad del medio rural. Este medio constituye un ámbito esencial para el diseño de estrategias, y la noción de multifuncionalidad del medio rural representa un argumento consistente para la elaboración de políticas que, aprovechando de forma sostenible los recursos existentes, contribuyan al incremento del bienestar, no solo de los agricultores, sino de todo el conjunto de la población rural.

- La incorporación de jóvenes agricultores. 


\section{Conclusiones}

Partiendo de un planteamiento que prioriza el carácter del territorio como recurso, un aprovechamiento inteligente del capital territorial es uno de los aspectos de los que depende el desarrollo de una región. Las estrategias de desarrollo integral deben incluir entre sus ejes de actuación la valorización de dicho capital. El territorio es, al mismo tiempo, un factor de identidad local, de generación de riqueza y empleo, de diversificación productiva, de organización y cohesión social, de innovación, de calidad, de producción y gestión de bienes públicos, de suministro de bienes y servicios culturales, etc. En definitiva, es un recurso multifuncional que integra elementos para impulsar el desarrollo.

Cada vez se valoran más determinados elementos inmateriales y algunas actividades que se encuentran asociados al hecho cultural, o sea, a la propia identidad territorial. El paisaje, la arquitectura popular, las fiestas y tradiciones, la artesanía o la gastronomía se erigen como componentes fundamentales de cara a una nueva concepción del desarrollo en zonas rurales cuyo valor añadido reside, precisamente, en el poder que les confiere su pertenencia a la cultura y el patrimonio local. La calidad del paisaje es considerada, en zonas que cuentan con gran potencial turístico como Andalucía, un aspecto fundamental para promover el desarrollo rural y regional. En este sentido, los paisajes del olivar andaluces no son una excepción. Los diferentes valores de estos paisajes son componentes claves del capital territorial andaluz y pueden contribuir al desarrollo rural y regional en un sentido amplio (económico, social y medioambiental). Ahora bien, la diversidad de estos paisajes exige que no sean tratados como un sector homogéneo con problemáticas similares. Muy al contrario, este cultivo se desarrolla en zonas edafo-climáticas diferentes, que dan lugar a diversos tipos de olivicultura, y que tienen una capacidad igualmente diferente de satisfacer las demandas sociales.

Bajo la presión de una competencia creciente, los territorios más innovadores buscan nuevas oportunidades para los procesos de desarrollo, activando los recursos genéricos para convertirlos en específicos, lo que conlleva una revalorización de su territorio. Este último puede considerarse como un auténtico activo de cara al impulso de tales procesos, dado que representa la base sobre la que se sustentan actividades diversas, entre ellas, algunas relacionadas con el turismo. Desde hace unos años se observan cambios en los hábitos de muchos turistas, incluidos aquellos que eligen Andalucía como destino, dado que orientan sus preferencias hacia otras modalidades turísticas distintas a la clásica de sol y playa. En consonancia con esta evolución, la utilización de los espacios de interior y la reconversión del capital territorial ubicado en zonas rurales para usos turísticos, vienen acompañados de la consideración de aspectos como la autenticidad, la identidad cultural de los territorios, la revalorización de las raíces y una mayor concienciación medioambiental de las sociedades urbanas.

En el ámbito de la Unión Europea los retos de la agricultura se concretan en la capacidad productiva del sector agrario, en la creciente diversidad de dicho sector y de las zonas rurales tras las sucesivas incorporaciones de nuevos países miembros, y en las exigencias de los ciudadanos en relación con el medio ambiente, la seguridad y calidad de los alimentos, la nutrición, la salud y el bienestar animal, las cuestiones fitosanitarias, la preservación del paisaje y de la biodiversidad y el fenómeno del cambio climático. La reforma de la PAC, para el sexenio 2014-2020, se va a apoyar en un nuevo paradigma que considere también las denominadas funciones no comerciales (sin mercado) de la agricultura, promoviendo así la seguridad alimentaria, la conservación del medio ambiente, la lucha contra el cambio climático y el equilibrio social y territorial, con el fin de instaurar un crecimiento más sostenible, más inteligente y más inclusivo en las zonas rurales de Europa. En caso contrario, aumentaría el riesgo de que desaparezca la actividad agraria en aquellas zonas que no alcancen un nivel suficiente de competitividad en los mercados, al considerarse solamente la función productiva e ignorarse el resto de costes y beneficios sociales vinculados a los sistemas agrarios.

En Andalucía el olivar presenta peculiaridades con respecto a otras zonas productivas, o con respecto a otros cultivos de la propia región. Se trata de la primera especialización productiva de la agricultura andaluza y tiene 
una gran importancia social. Aproximadamente el $17 \%$ de la superficie regional está ocupada por olivos, lo cual hace que las circunstancias de este cultivo sean determinantes para la realidad socioeconómica, cultural y medioambiental de esta comunidad. Como ha quedado puesto de manifiesto a partir del análisis DAFO, la vulnerabilidad del olivar andaluz es más que evidente debido a los riesgos a los que está expuesto: medioambientales (erosión), agronómicos (plagas), sociales (envejecimiento de los agricultores), territoriales (el futuro de numerosos pueblos depende de este cultivo) o los de tipo económico (derrumbe de los precios e incrementos de los costes de producción). Además, en este sector, gran parte de las rentas netas que obtienen los agricultores proceden de las ayudas instrumentadas desde la PAC, cuya evolución, como ya se ha mencionado, va a determinar un nuevo escenario para el sexenio 2014-2020. En el caso concreto de la Comunidad Andaluza, se abre una nueva etapa en la dinámica de los paisajes del olivar. Habrá que impulsar iniciativas para que los productores puedan optar por diferentes alternativas: reestructuración, reconversión hacia otros cultivos o actividades, o bien la preservación o continuidad sobre la base de la contribución al desarrollo rural sostenible, dado el carácter multifuncional y generador de externalidades positivas del olivar. En definitiva, Andalucía puede aprovechar la multifuncionalidad de sus paisajes del olivar, un patrimonio indisoluble a su realidad, a su identidad y a sus gentes. Y no solo por su importancia económica, sino porque ha generado, a lo largo del tiempo, una cultura específica que tiene en este cultivo y su fruto su razón de ser.

La necesidad de encontrar alternativas de diversificación económica para muchas localidades ubicadas en zonas olivareras y que presentan un alto grado de dependencia del sector primario, junto con las nuevas tendencias para zonas de interior, surgidas en el sector del turismo, otorgan un papel especialmente relevante a aquellas actividades que permiten capturar la esencia de esa cultura que rodea al mundo del olivo y del aceite de oliva. Se trata de prácticas turísticas con las que diversificar las actividades económicas en el medio rural andaluz, vinculando la puesta en valor del patrimonio territorial (los paisajes del olivar) con la promoción del desarrollo rural y regional: la generación de empleo, la fijación de la población, la creación de capital social en el medio rural (pertenencia a cooperativas $u$ otros colectivos) y la preservación de los paisajes del olivar y del patrimonio cultural asociado a los mismos.

El oleoturismo representa una nueva propuesta para disfrutar del tiempo libre que conjuga cultura, naturaleza y gastronomía. Es una forma de difundir el modo de vida de la tierra, las bondades del aceite de oliva y de disfrutar de todo lo relacionado con el olivo. Además, dinamiza las actividades económicas tradicionales y revaloriza las características culturales locales, aportando alternativas reales de empleo en zonas rurales de Andalucía. Se trata pues de un complemento económico, sobre todo, cuando la producción de aceite deja de ser rentable.

En la región de la oleicultura por excelencia, esta oferta puede complementarse con la del turismo de naturaleza, el turismo rural y también con el turismo cultural de las ciudades Patrimonio de la Humanidad localizadas en ella. Serán las Administraciones Públicas las que deban implementar programas que contribuyan a potenciar y consolidar este segmento turístico, considerado estratégico tanto para el desarrollo territorial como para el económico, dado su alto valor añadido. En definitiva, el oleoturismo es un producto turístico con gran potencial de crecimiento que puede favorecer el desarrollo económico y territorial de algunas comarcas andaluzas de interior, y constituir una oferta turística de calidad que dé respuesta a las expectativas de los visitantes.

\section{Referencias bibliográficas}

AFORO DE OLIVAR. CAMPAÑA 20132014. Datos básicos del olivar andaluz. Consejería de Agricultura, Pesca y Desarrollo Rural. Junta de Andalucía, 2013. Disponible en Internet: http://www.juntadeandalucia.es/ agriculturaypesca/portal/export/sites/default/ comun/galerias/galeriaDescargas/cap/servicio-estadisticas/estadisticas-agrarias/avances/ AFORO_2013-2014_olivar.pdf.

ALLAIRE, G. \& BOYER, R. (editors). La grande transformation de l'agriculture. Collec- 
tion Economie Agricole et Agro-alimentaire. Paris: INRA/ECONOMICA, 1995.

ALLAIRE, G. Transformation des systémes d'innovation: Réflexions á partir des nouveIles fonctions de I'agriculture. In: ALLAIRE, G.; HUBERT, B. \& LANGLET, A. (editors). CoIloque Nouvelles Fonctions de 1'agriculture et de 1'espace rural. Enjeux et défis identifiés par la recherche. Paris: INRA. Actes du Colloque de Toulouse, 17-18 décembre, 1996.

ALTIERI, M. El estado del arte de la Agroecología y su contribución al desarrollo rural en América Latina. Berkley: Universidad de California. Consorcio Latinoamericano sobre Agroecología y Desarrollo (CLADES), 1993.

BALDOCK, D.; BEAUFOY, G.; BENNETT, G. \& CLARK, J. Nature conservation and new directions in the Common Agricultural Policy. London: IEEP, 1993.

BARAJA, E. La Tierra de Campos. En: MOLINERO, F.; OJEDA, J. y TORT, J. (coordinadores). Los paisajes agrarios de España. Caracterización, evolución y tipificación. Madrid: Ministerio de Medio Ambiente, Medio Rural y Marino, 2010, p. 218-239.

BARNETT, V.; LANDAY, S. \& WELHAM, J. Measuring Sustainability. Journal of Environmental Statistics, 1994, № 1, p. 21-36.

BAZIN, G. Le développement de 1'agritourisme en France. In: Rencontre International sur le Développement des Zones Défavorisées Méditerranéenes. Fes-Sefrou (Maroc), 1-4 novembre 1993.

BEAUFOY, G.; BALDOCK, D. \& CLARK, J. The nature of farming: Low intensity farming systems in nine European countries. London: IEEP, 1994.

BENNETT, G. (editor). Cultural landscapes. The conservation challenge in a changing Europe. Arnhem and London: Institute for European Environmental Policy, 1996.

BIGNAL, E.M. \& MCCRACKEN, D.I. The nature conservation value of European traditional farming systems. Environmental Reviews, 2000, Vol. 8, № 3, p. 149-171.
CADENAS, A. (editor). Agricultura y desarrollo sostenible. Madrid: Ministerio de Agricultura, Pesca y Alimentación. Secretaría General Técnica, 1995.

CALATRAVA, J. Análisis de potencialidad del turismo rural como elemento generador de rentas complementarias en zonas en depresión socioeconómica: el caso de Las Alpujarras granadinas. En: Coloquio HispanoFrancés sobre espacios Rurales. Tomo II. Madrid: MAPA, 1983.

CALATRAVA, J. \& GONZÁleZ, M.C. Potentialisation des éléments culturaux dans les processus de développement rural: le cas de 1'Alpujarra. In: Suds et lles Méditerranéennes: Terres d'initiatives ou terres d'assistance? Ajaccio: Edition Universitaires de Corse, 1992.

CALATRAVA, J. y RUIZ., P. El agroturismo. Leader Magazine, 1993, N4, p. 6-9.

CALATRAVA, J. y SAYADI, S. Turismo y desarrollo rural: un necesario equilibrio. En: Curso de Verano Estrategias Turísticas y Desarrollo Rural. Oportunidades y Limitaciones. Guadix: Universidad de Granada. Centro Mediterráneo, 8 de Septiembre de 1997.

CALATRAVA, J. \& SAYADI, S. Interdisciplinarité et Agriculture Durable: Implication pour 1'Enseignement Agricole. In: Proceedings Jounées d'Etudes du REIFEA (Réseau Interuniversitaire de Formation des Enseignants Agricoles), Toulouse, 2001.

CAMPOS, P. El valor económico total de los sistemas agroforestales. Agricultura y Sociedad, 1994, № 71, p. 243-256.

CAMPOS, P.; DE ANDRÉS, R. y URZAINQUI, E. Valor Económico Total de un espacio de interés natural. La dehesa del área de Monfragiüe. En: AZQUETA, D. y PÉREZ, L. (editores). Gestión de Espacios Naturales. Madrid: Ed. McGraw-Hill, 1996.

CASABIANCA, F. Qualité et valorisation des produits régionaux dans le développement des zones marginalisées. En: Rencontre Internationale sur le Développement des Zones Défavorisées Méditerranéennes. FesSefrou (Maroc), 1-4 Novembre 1993. 
CASTILLO RODRÍGUEZ, C. La conceptualización de los segmentos turísticos en Andalucía: una breve aproximación. Turydes, 2011, Vol. 4, № 10. Disponible en Internet: http://www.eumed.net/rev/turydes/10/ccr.pdf.

COMMISSION OF THE EUROPEAN COMMUNITIES. The development and future of the CAP. Brussels: Communication of the commission to the council, COM (91) 100 final, February, 1991.

CONSEJERÍA DE AGRICULTURA Y PESCA. Ley del Olivar. Sevilla: Documento de reflexión. Grupo de Ordenación del Territorio y Desarrollo Rural, 2009.

CONSEJO DE EUROPA. Convenio Europeo del Paisaje. Florencia: Consejo de Europa, 2000.

DALY, E. y GAYO, D., Significado, conceptualización y procedimientos operativos del desarrollo sostenible: posibilidades de aplicación a la agricultura. En: CADENAS, A. (editor). Agricultura y desarrollo sostenible. Madrid: Ministerio de Agricultura, Pesca y Alimentación. Secretaria General Técnica, 1995.

DELGADO, B.; OJEDA, J.F.; INFANTE AMATE, J. y ANDREU, C. Los olivares andaluces y sus paisajes distintivos del mundo mediterráneo. Revista de Estudios Regionales, 2013, No 96, p. 267-291.

DUARTE ALONSO, A. \& NORTHCOTE, J. The development of olive tourism in Western Australia: a case study of an emerging tourism industry. International Journal of Tourism Research, 2010, Vol. 12, № 6, p. 696-708.

ENCUESTA SOBRE SUPERFICIES Y RENDIMIENTOS DE CULTIVOS 2012. Encuesta sobre superficies y rendimientos de cultivos. Análisis de las plantaciones de olivar en España. Madrid: Ministerio de Agricultura, Alimentación y Medio Ambiente. Secretaría General Técnica, 2013. Disponible en Internet: http:// www.magrama.gob.es/es/estadistica/temas/novedades/Olivar2012_tcm7-262578.pdf.

FAGGION, A. Le tourisme, Agent de dévelopement Economique, Social et Cultural. En: Coloquio Hispano-Francés sobre espacios Rurales. Tomo II. Madrid: MAPA, 1983.
FOOD AND AGRICULTURE ORGANIZATION OF THE UNITES NATIONS (FAO). EXperiencias de mercadeo de pequeños agricultores en el marco de proyectos de desarrollo rural integrado. Boletín de Servicios Agrícolas, 1992, n 102.

FORO EUROPEO DE LAS REGIONES OLIVARERAS. Bruselas: Marzo, 2012.

GÓMEZ-LIMÓN RODRÍGUEZ, J.A. y ARRIAZA BALMÓN, M. Evaluación de la sostenibilidad de las explotaciones de olivar en Andalucía. XIII Premio Unicaja de Investigación Agraria. Málaga: Analistas Económicos de Andalucía, 2011. Disponible en Internet: https://www.unicaja.es/resources/1320671483909.pdf.

GROLLEAU, H. Le tourisme rural dans les 12 etats membres de la CEE. Luxembourg: Office des Publications officielles des Communautés Européennes, 1987.

GUILLOU, M. La qualité, instrument de politique agricole? In: CERF, M.; AUBRY, C.; DE SAINTE MARIE, C.; HUBERT, B.; VALCESCHI$\mathrm{NI}, \mathrm{E}$. \& VISSAC, B. (editors). Qualité et systémes agraire. Techniques, lieux, acteurs. Etudes et Récherches sur les Systémes Agraires et le Développement № 28. Paris: INRA, 1994.

GUZMÁN ÁlVAREZ, J.R. El Palimpsesto cultivado. Propuesta de un catálogo de paisajes culturales históricos del olivar andaluz. En: I Congreso de la Cultura del Olivo. Jaén: 27 al 29 de octubre, 2005a.

GUZMÁN ÁLVAREZ, J.R. Catálogo de unidades territoriales del olivar andaluz. En: I Congreso de la Cultura del Olivo. Jaén: 27 al 29 de octubre de 2005b.

GUZMÁN ÁlVAREZ, J.R. y ZOIDO, F. El olivar andaluz en su dimensión paisajística. Espacio vivido y paisaje sentido. En: IZQUIERDO TOSCANO, J.M. (coordinador). Andalucía, el Olivar (capítulo 4). Sevilla: Editorial Juan Ramón Guillén, 2013.

HERMOSILLA PLA, J. (director). Los regadíos históricos españoles. Paisajes culturales, paisajes sostenibles. Madrid: Ministerio de Medio Ambiente y Medio Rural y Marino, 2010. 
HILDANHRAND SCHEID, A. Creación, conservación y gestión del paisaje un elemento clave para el desarrollo rural en Andalucía. Revista de Estudios Andaluces, 1993, No 19, p. 43-52.

LANE, B. Les stratégies du tourisme et le développement rural. In: Politique du tourisme et le tourisme international dans les pays de l'OCDE. París: OCDE, 1994.

LEY DEL OLIVAR DE ANDALUCÍA. SeviIla: BOJA N 205 de 19 de octubre de 2011.

LOUMOU, A. \& GIOURGA, C. Olive groves: "The life and identity of the Mediterranean". Agriculture and Human Values, 2003 Vol. 20, No 1, p. 87-95.

MATA, R. y FERNÁNDEZ, S. Paisajes y patrimonios culturales del agua. La salvaguarda del valor patrimonial de los regadíos tradicionales. Scripta Nova. Revista Electrónica de Geografía y Ciencias Sociales, 2010, Vol. XIV, $N^{\circ} 337$. Disponible en Internet: http://www. ub.edu/ geocrit/sn/sn-337.htm.

MATOS, A. El oleoturismo nos descubre una nueva faceta del olivar. Mercacei magazine, 2006, No 49, p. 60-89.

MILLÁN, G.; MORALES, E. y AGUdO, E.M. El oleoturismo como motor de desarrollo rural: La denominación de origen de Montoro-Adamuz. Mundo Agrario. Revista de Estudios Rurales, 2010, Vol. 11, № 21, p. 1-28.

MILLÁN, G.; ARJONA, J.M. \& AMADOR, L. A new market segment for olive oil: Olive oil tourism in the south of Spain. Agricultural Sciences, 2014, Vol. 5, No 3, p. 179-185.

MOLINA, V.; QUESADA, J.M. y RUIZ, I. Potencial del oleoturismo como diversificación económica del sector cooperativo agrario: el caso español. Revista de Ciencias Sociales, 2011, Vol. XVII, No 3, p. 533-541.

MOLINERO, F. La Ribera del Duero. En: MOLINERO, F.; OJEDA, J. Y TORT, J. (coordinadores). Los paisajes agrarios de España. Caracterización, evolución y tipificación. Madrid: Ministerio de Medio Ambiente, Medio Rural y Marino, 2010, p. 218-239.
NAREDO, J.M. y CAMPOS, P. La energía en los sistemas agrarios. Agricultura y Sociedad, 1980, N¹5, p. 17-113.

NOGUÉ, J. y SALA, P. El paisaje en la ordenación del territorio. Los catálogos de paisaje de Cataluña. Cuadernos Geográficos, 2008, No 43, p. 69-98.

ORGANIZACIÓN MUNDIAL DEL TURISMO. Políticas y Prácticas para el Turismo Mundial. Madrid, 2011.

ORTEGA VALCÁRCEL, J. El Patrimonio Territorial como recurso cultural y económico. En: CASTRILLO ROMÓN, M.A. y TREMIÑO SAN EMETERIO, C. (coordinadores). Revista Ciudades. Territorio y Patrimonio, 1998, No 4 , p. 33-48.

PAINTER, K. Does sustainable farming pay. Journal of Sustainable Agriculture, 1991, Vol. 1, No 3, p. 37-48.

PEARCE, D.W. \& TURNER, R.K. Economic of natural resource and the environment. Traducción española. Madrid: Colegio de Economistas de Madrid. Celeste Ediciones, 1990.

RODRÍGUEZ, E. y GÓMEZ., M.R. Turismo y desarrollo rural sostenible en la Alpujarra. En: $1^{a}$ Conferencia Internacional sobre Sierra Nevada: Conservación y Desarrollo Sostenible. Granada: Universidad de Granada. Sierra Nevada 96. Consejería de Medio Ambiente de la Junta de Andalucía y UNESCO, Vol. III, 1996, p. 151-171.

RUIZ GUERRA, I. Olive oil as a tourist resource: conceptual boundaries. Olivae, 2011, $N^{\circ} 115$, p. 32-47.

RUIZ GUERRA, I.; MOLINA MORENO, V. y MARTÍN LÓPEZ, V.M. El oleoturismo como atractivo turístico en el medio rural español. Papers de Turisme, 2011, No 49/50, p. 69-103.

SÁNCHEZ DE PUERTA, F. Extensión agraria y desarrollo rural. Madrid: Secretaría General Técnica. MAPA. Serie Estudios, N ${ }^{\circ} 123$, 1996.

SÁNCHEZ MARTÍNEZ, J.D.; GALLEGO SIMÓN, V.J. y ARAQUE JIMÉNEZ, E. El olivar andaluz y sus transformaciones recientes. 
Estudios Geográficos, 2011, Vol. 72, № 270, p. 203-229.

SAYADI, S. y CALATRAVA, J. El potencial agroturístico: análisis preliminar de un sondeo en La Alpujarra Alta Oriental Granadina. En: Curso de Verano: Estrategias Turísticas y Desarrollo Rural: Oportunidades y limitaciones. Guadix: Universidad de Granada. Centro Mediterráneo, 8 de Septiembre de 1997.

SAYADI, S. y CALATRAVA, J. Análisis funcional de los sistemas agrarios para el desarrollo rural sostenible: las funciones productiva, recreativa y estética de la agricultura en la alta alpujarra. Madrid: Ministerio de Agricultura, Pesca y Alimentación, Centro de Publicaciones, 2001.

SCHMITZ, M.F.; DE ARANZÁBAL, I.; AGUILERA, P.; RESCIA, A. \& PINEDA, F.D. Relationship between landscape typology and socioeconomic structure. Scenarios of change in Spanish cultural landscapes. Ecological Modelling, 2003, Vol. 168, № 3, p. 343-356.
SEVILLA, E. \& DENT, J.B. The role of farming systems Research/Extension in Guiding Low Input Systems Towards Sustainability: Agroecological Approach for Andalusia. In: DENT, J.B. \& McGREGOR, M.J. (editors). Rural and Farming Systems Analysis: European Perspectives. CAB Internacional, 1994.

SILVA PÉREZ, R. La dehesa vista como paisaje cultural: fisonomías, funcionalidades y dinámicas históricas. Ería: Revista cuatrimestral de Geografía, 2010, № 82, p. 143157.

SILVA PÉREZ, R. y OROZCO FRUTOS, G. Análisis territorial de la agricultura. Bases conceptuales y ensayo metodológico. Ciudad y Territorio: Estudios Territoriales, 2011, № 167, p. 33-52.

UNIDAD DE PROSPECTIVA DE LA CONSEJERÍA DE AGRICULTURA Y PESCA DE LA JUNTA DE ANDALUCÍA. El Olivar Andaluz. Sevilla: Junta de Andalucía, 2002. 